Published in final edited form as:

Nat Chem. ; 4(5): . doi:10.1038/nchem.1327.

\title{
A gold-catalysed enantioselective Cope rearrangement of achiral 1,5-dienes
}

\author{
Ryan J. Felix ${ }^{1}$, Dieter Weber ${ }^{1}$, Osvaldo Gutierrez², Dean J. Tantillo², ${ }^{2}$, and Michel R. \\ Gagné ${ }^{1, *}$ \\ ${ }^{1}$ Department of Chemistry, University of North Carolina at Chapel Hill, Chapel Hill, North Carolina \\ 27599-3290, USA \\ ${ }^{2}$ Department of Chemistry, University of California at Davis, Davis, California 95616, USA
}

\section{Abstract}

Since the discovery of the Cope rearrangement in the 1940s, no asymmetric variant of the rearrangement of achiral 1,5-dienes has emerged, despite the successes that have been achieved with its heteroatom variants (Claisen, aza-Cope, etc.). This article reports the first example of an enantioselective Cope reaction that starts from an achiral diene. The new gold(I) catalyst derived from double $\mathrm{Cl}^{-}$-abstraction of $\left((S)-3,5\right.$-xylyl-PHANEPHOS $\left.(\mathrm{AuCl})_{2}\right)$, has been developed for the sigmatropic rearrangement of alkenyl-methylenecyclopropanes. The reaction proceeds at low temperature and the synthetically useful vinylcyclopropane products are obtained in high yield and enantioselectivity. Density functional theory calculations predict that: (1) the reaction proceeds via a cyclic carbenium ion intermediate, (2) the relief of strain in the methylenecyclopropane moiety provides the thermodynamic driving force for the rearrangement and (3) metal complexation of the transition-state structure lowers the rearrangement barriers.

The Cope rearrangement is a textbook sigmatropic reaction of 1,5-dienes that occurs at 150 $200{ }^{\circ} \mathrm{C}$ and has been known for over 70 years ${ }^{1}$. Numerous variants of this rearrangement, including those subject to catalysis, have been reported to lower reaction temperatures, add functionality to the products and provide routes to chiral products in the case of the azaCope and Claisen variants ${ }^{2,3}$. Studies demonstrating efficient [1,3]-transfer of chirality in 1,5-dienes are consistent with a concerted reaction that proceeds through an ordered chairlike transition-state structure, a feature that has undoubtedly been key to the development of enantioselective hetero-Cope variants, Overman's Pd-catalysed allylic trichloroacetimidate rearrangement being especially noteworthy (Fig. 1a) $)^{4}$. The reaction most resembling an enantioselective Cope reaction was reported by the Davies group. They note that a powerful domino reaction ensues when a chiral $\mathrm{Rh}(\mathrm{II})$ vinylcarbene catalyst initiates an allylic $\mathrm{C}-\mathrm{H}$ insertion. This process is diverted mid-insertion by a competing Cope rearrangement to provide 1,5-dienes with excellent diastereo- and enantio-control (Fig. 1a) ${ }^{5,6}$.

\footnotetext{
(C) 2012 Macmillan Publishers Limited. All rights reserved.

*Correspondence and requests for materials should be addressed to D.J.T. and M.R.G. tantillo@chem.ucdavis.edu; mgagne@unc.edu. Author contributions

R.J.F., D.W. and M.R.G. conceived and designed the experiments. R.J.F. performed the experiments and analysed the data. R.J.F., D.J.T. and M.R.G. co-wrote the paper. O.G. and D.J.T. performed the DFT calculations. All authors discussed the results and commented on the manuscript.

Additional information

The authors declare no competing financial interests. Supplementary information and chemical compound information accompany this paper at www.nature.com/naturechemistry. Reprints and permission information is available online at http://www.nature.com/reprints.
} 
Generally speaking, the Cope rearrangement is constrained by the thermodynamics of alkene substitution in the reactants and products. That is, favourable reactions typically convert less-substituted alkenes into more-substituted alkenes, which leads to large classes (that is, directions) of the Cope rearrangement not being feasible ${ }^{7}$. To the problem of asymmetric induction, these subtle driving forces also lead to reversibility and the consequent loss of kinetic control, a prerequisite for highly asymmetric induction. The consumption of $\mathrm{C}-\mathrm{C}$ unsaturation ${ }^{8,9}$ along with the release of ring strain ${ }^{10-16}$, however, are forces that have been harnessed to drive rearrangement reactions in organic synthesis.

Described herein is an enantioselective methodology for the catalyst-controlled Cope rearrangement of achiral dienes that simultaneously solves issues related to reaction thermodynamics and kinetics. The former provides the means to reverse the normal thermodynamic control elements and allow products with $\pi$-bonds less substituted than those of the starting diene to be favoured, and simultaneously create an asymmetric route to synthetically valuable vinylcyclopropanes. Quantum mechanical calculations ${ }^{17}$ were used to assess the kinetic feasibility of competing mechanistic pathways and reveal the origins of their thermodynamic favourability.

\section{Results}

In the course of examining the reactivity of polyenes with a 1,5-substitution pattern we discovered that compounds with a terminal methylenecyclopropane preferentially rearrange to the Cope product rather than cascade through ionic pathways to polycyclic products ${ }^{18-20}$. For example, when triene 1a was reacted with $10 \mathrm{~mol} \% \mathrm{Ph}_{3} \mathrm{PAuNTf}_{2}$ (ref. 21; Tf = trifluoromethanesulfonyl) the vinylcyclopropane product 2a was obtained (Fig. 1b). Of significance in this reaction is the decrease in alkene substitution on going from the alkylidene cyclopropane to the vinylcyclopropane. Beginning with Overman's report of a $\mathrm{PdCl}_{2}(\mathrm{NCPh})_{2}$-catalysed Cope rearrangement of 1,5-dienes, a number of studies showed that electrophilic metal catalysts can mediate this reaction through a transient cyclocarbenium ion (A), which fragments to the Cope product under significantly milder conditions (room temperature (r.t.)) than those required under thermal conditions (150-200 ${ }^{\circ} \mathrm{C}$, Fig. 1b) ${ }^{22-25}$. Although the Cope reaction necessitates a product whose alkenes are more substituted than the starting diene, it and its variants (aza-Cope, oxy-Cope) have nevertheless found widespread use in organic synthesis ${ }^{26,27}$.

On observing the facile nature of the $\mathrm{Au}(\mathrm{I})$-catalysed rearrangement (r.t., two hours, Fig. 1b), other known catalysts for the Cope rearrangement were tested. Unfortunately, none were found to react at r.t. and elevated temperatures usually led to a large number of unidentified products; for example, $\mathrm{PdCl}_{2}\left(\mathrm{MeCN}_{2}\right.$ in $\mathrm{MeCN}, \mathrm{PdCl}_{2}(\mathrm{NCPh})_{2}$ in $\mathrm{MeCN}$ or tetrahydrofuran (THF) and $\mathrm{PtCl}_{2}$ in toluene ${ }^{22-24,28,29}$. The dearth of approaches to the asymmetric Cope rearrangement led us to search next for an enantioselective variant of the $\mathrm{Au}(\mathrm{I})$ catalyst ${ }^{30-38}$. To this end, the solvent, temperature and silver salt were optimized using the chiral bis(gold) catalyst $(R)$-xylyl-BINAP $(\mathrm{AuCl})_{2}\left(\mathrm{BINAP}=2,2^{\prime}\right.$ -

bis(diphenylphosphino)-1,1'-binaphthyl; see Supplementary Information), and this was followed by a screen of representative commercially available chiral ligands. Table 1 shows the results of this screening with compound $\mathbf{1 b}$.

The enantioselectivity was, in most cases, dishearteningly low, with $(R)$-xylyl-BINAP performing better than most of the other dipho-sphine ligands (34\% enantiomeric excess (e.e., $-20^{\circ} \mathrm{C}$ (Table 2, entry 2)). Monodentate ligands (Table 2, entry 11$)^{32}$ and chiral anions (Table 2, entry 12) did not fare better. Ligands that previously exhibited high asymmetric induction in $\mathrm{Au}(\mathrm{I})$ catalysis (Table 2, entries 3, 4 and 11) were unselective or unreactive. The catalyst derived from $(S)$-3,5-xylyl-PHANEPHOS(AuCl $)_{2}(\mathbf{4})$ 
(PHANEPHOS = 4,12-bis(diphenylphosphino)-[2.2]-paracyclophane), however, was uniquely enantioselective (Table 2, entry 10), representing its first effective use in $\mathrm{Au}(\mathrm{I})$ asymmetric catalysis $^{20,37}$. In the X-ray crystal structure of $\mathbf{4}$ shown in Fig. 1c, the long $\mathrm{Au}-$ Au distance (5.620 ̊) indicates that no Au...Au interactions are feasible in this inactivated form.

A second round of catalyst optimization was performed with $\mathbf{4}$, which led to the optimal conditions of $5 \mathrm{~mol} \%$ of $\mathbf{4}$ and $20 \mathrm{~mol}^{2}$ of $\mathrm{AgSbF}_{6}$ in a 1:9 mixture of dichloromethane (DCM) to 1,2-dichloroethane (1,2-DCE) at $-35^{\circ} \mathrm{C}$ (see Supplementary Information for details). This protocol was applied to various substrates, as reported in Table 2. Methylenecyclopropanes of this type were prepared in moderate yield via the Wittig reaction of the aldehyde precursor with cyclopropyltriphenylphosphonium bromide ${ }^{39}$. Alkyl- and aryl-substituted 1,5-dienes were good reactants with triene $\mathbf{1 a}$ and gave the highest enantioselectivity, 93\%. Good activity and selectivity were achieved with unfunctionalized alkyl and aromatic substrates (Table 2, entries 1-4) and a number of functional groups were tolerated, including tetrahydropyranyl (THP)- and acetyl-protected alcohols (Table 2, entries 7 and 8), free alcohols (Table 2, entry 9) and phenols (Table 2, entry 6). Although these more functionalized substrates required longer reaction times, the products were obtained in good yields and enantioselectivities. The diminished yield of $\mathbf{1 i}$ resulted from deleterious side reactions, although suitably protected variants made for good reactions. A protected amine substrate, naphthalimide $\mathbf{1 j}$, also underwent the Cope rearrangement to give $\mathbf{2} \mathbf{j}$, but additionally gave $23 \%$ of $\mathbf{3} \mathbf{j}$, the product of an unusual cyclopropene rearrangement. This cyclobutene product was not detected in any other reactions, but was documented previously under $\mathrm{PtCl}_{2} / \mathrm{CO}$ conditions ${ }^{14}$ by Fürstner on simple alkylidenecyclopropanes, and by Toste in pinacol-like ring expansion of cyclopropanols to cyclobutanones ${ }^{40}$. Compound $\mathbf{1 k}$, whose Cope product probably lies uphill in energy because of the additional penalty of loss of alkene conjugation to one phenyl ring, was unreactive (vide infra).

\section{Discussion}

To probe the energetics of the Cope rearrangement, several model compounds were studied using density functional theory (DFT) ${ }^{17,41,42}$. Reported structures were optimized using DFT (M06-2X/6-31G(d) in the gas phase for uncatalysed systems and in 1,2-DCE $\left(\mathrm{CPCM}^{43}\right.$ model) using M06/6-31G(d)-(LANL2DZ for Au) for organometallic systems) as implemented in

First, rearrangement in the absence of catalyst was examined. Although predicted barriers are high for these reactions, $\sim 30 \mathrm{kcal} \mathrm{mol}^{-1}$, the rearrangements are significantly exothermic due to the release of ring strain on rearrangement (Table 3$)^{44,45}$. As expected, methyl substitution at the $\mathrm{C} 5$ position $\left(\mathrm{R}^{1}\right)$ only slightly changes this thermodynamic preference, but greater effects are predicted for alkyl substitution at the C6 $\left(\mathrm{R}^{2}\right)$ position (Table 3, entries 3 and 2, respectively). In sum, the relief of ring strain in the Cope reaction overcomes the otherwise unfavourable conversion into a less substituted product and provides a novel route to versatile vinylcyclopropanes.

Consistent with this outcome is the failure of rearrangement reactions on methylenecyclopentene or acyclic dimethylated terminal alkene substrates, which lack the requisite ring strain. Methylenecyclobutene analogues, like methylenecyclopropanes, are reactive to gold catalysts, but give several products.

The Au-catalysed rearrangement was predicted to proceed via a cyclic intermediate (Fig. 2, akin to that proposed for Pd(II)-promoted Cope rearrangements (A, Fig. 1b) $)^{22-25}$. Even 
though the complexation of $\mathrm{Au}(\mathrm{I})$ to the methylenecyclopropane (Fig. 2b) is slightly less favourable than complexation to the trisubstituted olefin (Fig. 2a), the kinetically preferred pathway is that shown in Fig. 2b; that is, the pathway in which a tertiary carbocation substructure, rather than a secondary cyclopropylcarbinyl cation substructure, is formed. Overall, the rearrangement is predicted to proceed with a barrier of $\sim 15 \mathrm{kcal} \mathrm{mol}^{-1}$, which is $\sim 20 \mathrm{kcal} \mathrm{mol}^{-1}$ lower than that for the uncatalysed rearrangement (Table $3, \mathrm{R}^{1}=\mathrm{R}^{2}=\mathrm{Me}$ ). In addition, calculations on substrate 1a, which failed to cyclize (equation (1), Fig. 1b), predict that, although cation-olefin bicyclization is actually kinetically favoured by $\sim 7 \mathrm{kcal}$ $\mathrm{mol}^{-1}$ over the formation of $\mathbf{2 a}$, this process is less exergonic and reversible, allowing the product of Cope rearrangement to form preferentially (see Supplementary Information for further details). Additional calculations indicated that gold cations could, indeed, induce the rearrangement of methylenecyclopropanes into cyclobutenes (for example, $\mathbf{3 j}$ ), but the barrier for such a process is predicted to be higher (by more than $10 \mathrm{kcal} \mathrm{mol}^{-1}$ ) than that for the Cope rearrangement (see Supplementary Information for details). The competitiveness of this process for $\mathbf{1} \mathbf{j}$ is intriguing and will be investigated independently.

In conclusion, a new chiral $\mathrm{Au}(\mathrm{I})$ catalyst was developed for the enantioselective Cope rearrangement of alkenyl-methylenecyclopropanes. This is the first example of a Cope reaction in which the enantioselectivity is not provided by either a pre-existing stereocentre or through a multistep sequence. The reaction is applicable to alkyl, aromatic and oxygenand nitrogen-containing substrates, with high yields and good-to-excellent enantioselectivities. Quantum chemical calculations show that the reaction is thermodynamically driven by the relief of ring strain from the cyclopropylidene moiety, and that the $\mathrm{Au}(\mathrm{I})$ catalyst greatly lowers the barrier for rearrangement. The type of strain relief described herein has potential as a general tool for the development of alternatives to otherwise unfavourable sigmatropic reactions ${ }^{11,12}$.

\section{Methods}

Characterization details for all new compounds and representative synthetic procedures, as well as complete $\mathrm{X}$-ray diffraction data, along with coordinates and energies for all computed structures, and the complete reference 17 and additional details on results from computations, are available in the Supplementary Information.

\section{General procedure for the preparation of substrates by the Wittig reaction}

To a flame-dried Schlenk flask loaded with a suspension of dry $\mathrm{NaH}(0.075 \mathrm{~g}, 3.15 \mathrm{mmol}$, 1.3 equiv.) in THF ( $13 \mathrm{ml})$ under $\mathrm{N}_{2}$ atmosphere was added cyclopropyltriphenylphosphonium bromide $(1.21 \mathrm{~g}, 3.15 \mathrm{mmol}, 1.3$ equiv. $)$ at r.t. The reaction flask was then equipped with a condenser and heated to $62{ }^{\circ} \mathrm{C}$ for 18 hours. To the resulting orange suspension was then added the aldehyde precursor (of $1,0.469 \mathrm{~g}, 2.42$ mmol, 1 equiv.) and tris(2-(2-methoxyethoxy)ethyl)amine $(0.077 \mathrm{ml}, 0.242 \mathrm{mmol}, 0.1$ equiv.) in THF ( $4 \mathrm{ml})$. The reaction was stirred for two hours at $62{ }^{\circ} \mathrm{C}$ before cooling to r.t. and quenching with saturated aqueous $\mathrm{NaHCO}_{3}$. The reaction was diluted with deionized $\mathrm{H}_{2} \mathrm{O}$ and $\mathrm{Et}_{2} \mathrm{O}$ before separating the layers. The aqueous layer was extracted with $\mathrm{Et}_{2} \mathrm{O}$ (twice) and the combined organic layers were then washed with brine (twice). The organic layer was dried over $\mathrm{MgSO}_{4}$, filtered and concentrated in vacuo. Purification by silica gel chromatography (hexanes) provided the product compound (1) as a colourless oil $(0.283 \mathrm{~g}$, $53 \%$ ). A small amount of $\mathrm{CH}_{2} \mathrm{Cl}_{2}$ was used to load the material onto the column.

\section{General procedure for the $\mathrm{Au}(\mathrm{I})$-catalysed Cope rearrangement}

To a vial loaded with silver hexafluoroantimonate ( $3.2 \mathrm{mg}, 0.0092 \mathrm{mmol}, 0.2$ equiv.) was added a 1:9 $\mathrm{CH}_{2} \mathrm{Cl}_{2}: 1,2$-DCE solution $(1 \mathrm{ml})$. Au(I) catalyst $4(2.6 \mathrm{mg}, 0.0023 \mathrm{mmol}, 0.05$ 
equiv.) was then added and the reaction stirred at r.t. for 15 minutes. The reaction was then placed into a NesLab Cryobath CB-80 maintained at $-35^{\circ} \mathrm{C}$ and stirred for 10 minutes before the addition of $\mathbf{1 a}(10 \mathrm{mg}, 0.046 \mathrm{mmol}, 1$ equiv.). The reaction was then stirred for 18 hours at $-35^{\circ} \mathrm{C}$ before concentrating the reaction in vacuo, after which the product was isolated by a silica gel pipette column (hexanes) to give 2a as a colourless oil ( $9.4 \mathrm{mg}, 94 \%)$.

\section{Supplementary Material}

Refer to Web version on PubMed Central for supplementary material.

\section{Acknowledgments}

The University of North Carolina group acknowledges the National Institute of General Medicine (GM-60578), D.W. acknowledges the Fulbright Foreign Student Program, D.J.T. acknowledges support from the ACS-PRF program (49119-ND4) and the National Science Foundation's Partnership for Advanced Computational Infrastructure (CHE-030089, Pittsburgh Supercomputer Center) and O.G. acknowledges R.M. Hussing, and M. and L. Defenbaugh for support.

\section{References}

1. Cope AC, Hardy EM. The introduction of substituted vinyl groups. V A rearrangement involving the migration of an allyl group in a three-carbon system. J Am Chem Soc. 1940; 62:441-444.

2. Nubbemeyer U. Recent advances in asymmetric [3,3]-sigmatropic rearrangements. Synthesis. 2003:961-1008.

3. Allin SM, Baird RD. Development and synthetic applications of asymmetric [3,3]-sigmatropic rearrangements. Curr Org Chem. 2001; 5:395-415.

4. Watson MP, Overman LE, Bergman RG. Kinetic and computational analysis of the palladium(II)catalyzed asymmetric allylic trichloroacetimidate rearrangement: development of a model for enantioselectivity. J Am Chem Soc. 2007; 129:5031-5044. [PubMed: 17402733]

5. Hansen JH, et al. On the mechanism and selectivity of the combined C-H activation/Cope rearrangement. J Am Chem Soc. 2011; 133:5076-5085. [PubMed: 21384883]

6. Lian Y, Davies HML. Combined C-H functionalization/Cope rearrangement with vinyl ethers as a surrogate for the vinylogous Mukaiyama aldol reaction. J Am Chem Soc. 2011; 133:11940-11943. [PubMed: 21739977]

7. Hoffmann R, Stohrer W-D. Cope rearrangement revisited. J Am Chem Soc. 1971; 93:6941-6948.

8. Wendt KU, Schulz GE, Corey EJ. Enzyme mechanisms for polycyclic triterpene formation. Angew Chem Int Ed. 2000; 39:2812-2833.

9. Yoder RA, Johnston JN. A case study in biomimetic total synthesis: polyolefin carbocyclizations to terpenes and steroids. Chem Rev. 2005; 105:4730-4756. [PubMed: 16351060]

10. Rubin M, Rubina M, Gevorgyan V. Transition metal chemistry of cyclopropenes and cyclopropanes. Chem Rev. 2007; 107:3117-3179. [PubMed: 17622181]

11. Lu B-L, Dai L, Shi M. Strained small rings in gold-catalyzed rapid chemical transformations. Chem Soc Rev. 201210.1039/C2CS15295A

12. Seiser T, Cramer N. Enantioselective metal-catalyzed activation of strained rings. Org Biomol Chem. 2009; 7:2835-2840. [PubMed: 19582290]

13. Leemans E, D'hooghe M, De Kimpe N. Ring expansion of cyclobutylmethylcarbenium ions to cyclopentane or cyclopentene derivatives and metal-promoted analogous rearrangements. Chem Rev. 2011; 111:3268-3333. [PubMed: 21488634]

14. Fürstner A, Aïssa C. $\mathrm{PtCl}_{2}$-catalyzed rearrangement of methylenecyclopropanes. J Am Chem Soc. 2006; 128:6306-6307. [PubMed: 16683781]

15. Seiser T, Saget T, Tran DN, Cramer N. Cyclobutanes in catalysis. Angew Chem Int Ed. 2011; 50:7740-7752. 
16. Mauleón P, Krinsky JL, Toste FD. Mechanistic studies on Au(I)-catalyzed [3,3]-sigmatropic rearrangements using cyclopropane probes. J Am Chem Soc. 2009; 131:4513-4520. [PubMed: $19275228]$

17. Frisch, MJ., et al. GAUSSIAN09, Revision A.02. Gaussian, Inc; Wallingford CT: 2009.

18. Sokol JG, Korapala CS, White PS, Becker JJ, Gagné MR. Terminating platinum-initiated cationolefin reactions with simple alkenes. Angew Chem Int Ed. 2011; 50:5658-5661.

19. Sethofer SG, Meyer T, Toste FD. Gold(I)-catalyzed enantioselective polycyclization reactions. J Am Chem Soc. 2010; 132:8276-8277. [PubMed: 20518531]

20. Pradal A, Chao C-M, Vitale MR, Toullec PY, Michelet V. Asymmetric Au-catalyzed domino cyclization/nucleophile addition reactions of enynes in the presence of water, methanol and electron-rich aromatic derivatives. Tetrahedron. 2011; 67:4371-4377.

21. Mézailles N, Ricard L, Gagosz F. Phosphine gold(I) bis-(trifluoromethanesulfonyl)imidate complexes as new highly efficient and air-stable catalysts for the cycloisomerization of enynes. Org Lett. 2005; 7:4133-4136. [PubMed: 16146370]

22. Overman LE, Renaldo AF. Mechanism of the palladium dichloride catalyzed Cope rearrangement of acyclic dienes. A substituent effect study. J Am Chem Soc. 1990; 112:3945-3949.

23. Nakamura H, Iwama H, Ito M, Yamamoto Y. Palladium(0)-catalyzed Cope rearrangement of acyclic 1,5-dienes. Bis( $\pi$-allyl)palladium(II) intermediate. J Am Chem Soc. 1999; 121:1085010851.

24. Fanning KN, Jamieson AG, Sutherland A. Palladium(II)-catalyzed rearrangement reactions. Curr Org Chem. 2006; 10:1007-1020.

25. Siebert MR, Tantillo DJ. Transition-state complexation in palladium-promoted [3,3] sigmatropic shifts. J Am Chem Soc. 2007; 129:8686-8687. [PubMed: 17585765]

26. Nowicki J. Claisen, Cope and related rearrangements in the synthesis of flavour and fragrance compounds. Molecules. 2000; 5:1033-1050.

27. Blechert S. The hetero-Cope rearrangement in organic synthesis. Synthesis. 1989:71-82.

28. Koh JH, Mascarenhas C, Gagné MR. Pd(II)-catalyzed cyclogeneration of carbocations: subsequent rearrangement and trapping under oxidative conditions. Tetrahedron. 2004; 60:7405-7410.

29. Korotchenko VN, Gagné MR. Palladium-catalyzed cyclization of 1, $\omega$-dienols: multiple ways to intramolecularly trap a carbocation. J Org Chem. 2007; 72:4877-4881. [PubMed: 17530903]

30. Fürstner A. Gold and platinum catalysis - a convenient tool for generating molecular complexity. Chem Soc Rev. 2009; 38:3208-3221. [PubMed: 19847352]

31. Li Z, Brouwer C, He C. Gold-catalyzed organic transformations. Chem Rev. 2008; 108:32393265. [PubMed: 18613729]

32. Gorin DJ, Sherry BD, Toste FD. Ligand effects in homogeneous Au catalysis. Chem Rev. 2008; 108:3351-3378. [PubMed: 18652511]

33. Widenhoefer RA. Recent developments in enantioselective gold(I) catalysis. Chem Eur J. 2008; 14:5382-5391. [PubMed: 18442031]

34. Fürstner A, Davies PW. Catalytic carbophilic activation: catalysis by platinum and gold $\pi$ acids. Angew Chem Int Ed. 2007; 46:3410-3449.

35. Hashmi ASK. The catalysis gold rush: new claims. Angew Chem Int Ed. 2005; 44:6990-6993.

36. Kleinbeck F, Toste FD. Gold(I)-catalyzed enantioselective ring expansion of allenylcyclopropanols. J Am Chem Soc. 2009; 131:9178-9179. [PubMed: 19530649]

37. Hamilton GL, Kang EJ, Mba M, Toste FD. A powerful chiral counterion strategy for asymmetric transition metal catalysis. Science. 2007; 317:496-499. [PubMed: 17656720]

38. Tarselli MA, Chianese AR, Lee SJ, Gagné MR. Gold(I)-catalyzed asymmetric cycloisomerization of eneallenes into vinylcyclohexenes. Angew Chem Int Ed. 2007; 46:6670-6673.

39. Stafford JA, McMurry JE. An efficient method for the preparation of alkylidenecyclopropanes. Tetrahedron Lett. 1988; 29:2531-2534.

40. Sethofer SG, Staben ST, Hung OT, Toste FD. Au(I)-catalyzed ring expanding cycloisomerization: total synthesis of ventricosene. Org Lett. 2008; 10:4315-4318. [PubMed: 18759435]

41. Zhao Y, Truhlar DG. The M06 suite of density functionals for main group thermochemistry, thermochemical kinetics, noncovalent interactions, excited states, and transition elements: two 
new functionals and systematic testing of four M06-class functionals and 12 other functionals. Theor Chem Acc. 2008; 120:215-241.

42. Zhao Y, Truhlar DG. Density functionals with broad applicability in chemistry. Acc Chem Res. 2008; 41:157-167. [PubMed: 18186612]

43. Barone V, Cossi M. Quantum calculation of molecular energies and energy gradients in solution by a conductor solvent model. J Phys Chem A. 1998; 102:1995-2001.

44. Johnson WTG, Borden WT. Why are methylenecyclopropane and 1-methylcyclopropene more 'strained' than methylcyclopropane? J Am Chem Soc. 1997; 119:5930-5933.

45. Bach RD, Dmitrenko O. Strain energy of small ring hydrocarbons. Influence of C-H bond dissociation energies. J Am Chem Soc. 2004; 126:4444-4452. [PubMed: 15053635] 
a
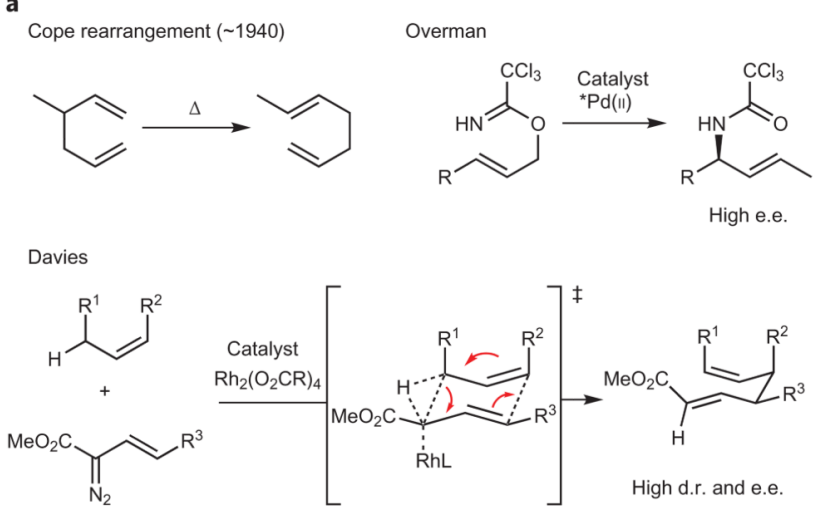

b

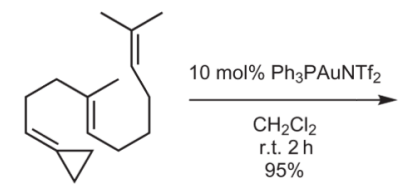

1a

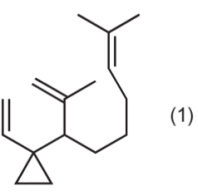

2a

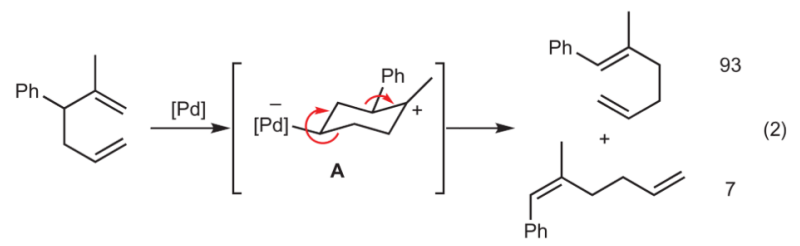

c
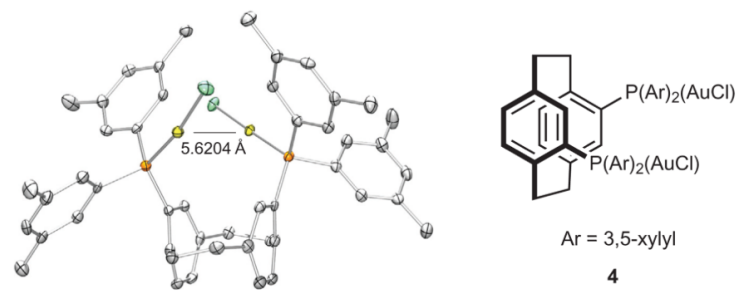

4

Figure 1. Transition-metal catalysed Cope rearrangements

a, The Cope rearrangement has been known for over 70 years, and although there are enantioselective variants (a, Overman) and intermolecular processes that resemble the Cope rearrangement (a, Davies), no asymmetric variants had been developed. b, The Au-catalysed Cope rearrangement of 1a to vinylcyclopropane 2a is conjectured to operate by electrophilic activation of the substrate, resembling the Pd-catalysed Cope rearrangement discovered by Overman. c, ORTEP representation of $\mathbf{4}$ with 50\% probability ellipsoids; hydrogen atoms and two solvent molecules (benzene) are omitted for clarity. Au-Au distance is $5.6204 \AA$. d.r. =diastereomeric ratio; $\mathrm{L}=$ ligand. 


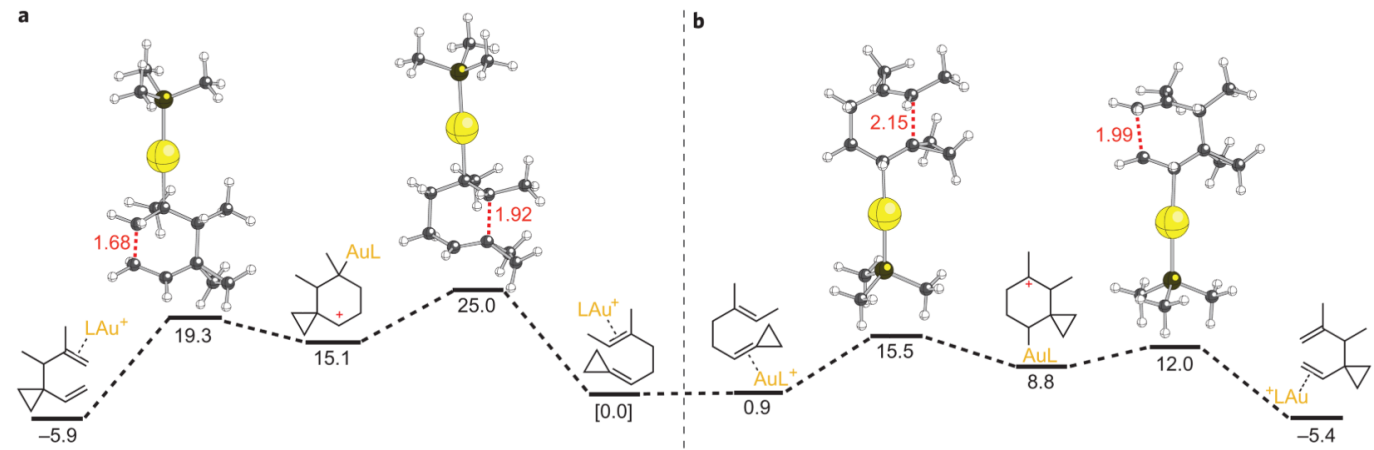

Figure 2. Computational investigation of the rearrangement pathway $\mathbf{a}, \mathbf{b}$, Two pathways for the $\mathrm{Au}^{+}-\mathrm{PMe}_{3}$-promoted Cope rearrangement of the $\mathrm{R}^{1}=\mathrm{R}^{2}=\mathrm{Me}$ system were investigated. In the first pathway (a) the Au catalyst activates the dimethyl substituted alkene. In the second pathway (b) the Au catalyst activates the cyclopropylsubstituted alkene. The calculations clearly show the latter pathway to be more favourable as judged by its lower barrier heights. The relative free energies ( $\mathrm{kcal} \mathrm{mol}^{-1}$, at $298 \mathrm{~K}$ ) for stationary points were calculated using M06 with the 6-31G(d) basis set for P, C and H, and LANL2DZ for Au, in 1,2-DCE (CPCM). ${ }^{17,41,42}$ Selected distances are given in $\AA$. L =ligand. 
Table 1

Ligand optimization for the $\mathrm{Au}(\mathrm{I})$-catalysed Cope rearrangement of $1 \mathrm{~b}^{*}$.

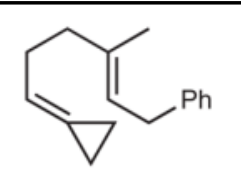

$1 \mathrm{~b}$

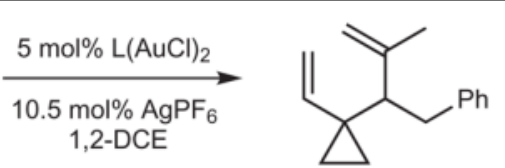

$2 b$

\begin{tabular}{llll}
\hline Entry $^{*}$ & Ligand (L) & $\boldsymbol{T}\left({ }^{\circ} \mathbf{C}\right)$ & e.e. $(\%)^{\dagger}$ \\
\hline 1 & $(R)$-xylyl-BINAP & 0 & 28 \\
2 & $(R)$-xylyl-BINAP & -20 & 34 \\
3 & $(R)$-xylyl-MeO-BIPHEP & -20 & 19 \\
4 & $(R)$-DTBM-SEGPHOS & -20 & 25 \\
5 & $(R)$-SEGPHOS & -20 & 16 \\
6 & $(R)$-DIFLUORPHOS & -20 & 9 \\
7 & $(R)$-xylyl-SDP & -20 & 5 \\
8 & $(R, R)$-Me-DuPHOS & 0 & 2 \\
9 & $(R)$-SYNPHOS & 0 & 15 \\
10 & $(S)$-3,5-xylyl-PHANEPHOS $(4)$ & -20 & 79 \\
11 & $(S)$-SIPHOS-PE & 0 & 7 \\
12 & Ag- $(R)-(5)$ & r.t. & - \\
\hline
\end{tabular}

* Reaction conditions: catalyst (5 mol\%), AgPF6 (10.5 mol\%), 1,2-DCE, 18 hours.

${ }^{\dagger}$ e.e. determined by chiral gas chromatography (GC). BIPHEP, 2,2'-bis(diphenylphosphino)-1,1'-biphenyl; DTBM, 3,5-di- $t$-butyl-4methoxyphenyl; SEGPHOS, 5,5'-bis(diphenylphosphino)-4,4'-bi-1,3-benzodioxole; DTBM-SEGPHOS, 5,5'-bis[di(3,5-di- $t$-butyl-4methoxyphenyl)phosphino]-4,4'-bi-1,3-benzodioxole; DIFLUORPHOS, 5,5'-bis(diphenylphosphino)-2,2,2',2'-tetrafluoro-4,4'-bi-1,3benzodioxole; SDP, 7,7'-bis(diphenylphosphino)-2,2',3,3'-tetrahydro-1,1'-spirobiindane; $(R, R)$-Me-DuPHOS, 1,2-bis( (2R,5R)-2,5dimethylphospholano)benzene; SYNPHOS, 6,6'-bis(diphenylphosphino)-2,2',3,3'-tetrahydro-5,5'-bi-1,4-benzodioxin; SIPHOS-PE, 10,11,12,13tetrahydrodiindeno[7,1-de: $1^{\prime}, 7^{\prime}$-fg $][1,3,2]$ dioxaphosphocin-5-bis $[(R)$-1-phenylethyl $]$ amine. 
Table 2

Reaction scope under optimized conditions with $(S)$-3,5-xylyl-PHANEPHOS $(\mathrm{AuCl})_{2}{ }^{*}$.

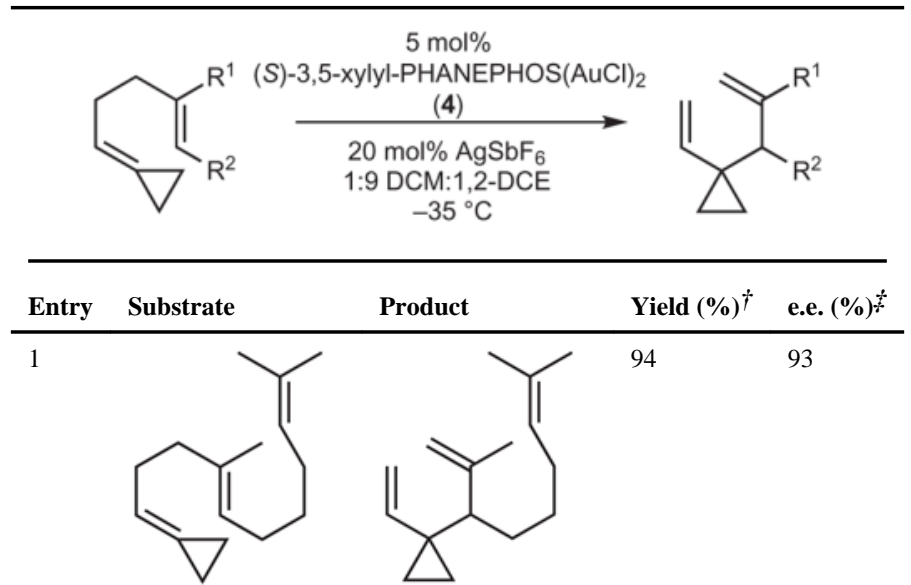

1a

2<smiles>CC1=CC(=CCCc2ccccc2)CC1</smiles>

$1 \mathbf{b}$

3<smiles>CCC=C(CC)CCC=C1CC1</smiles>

$1 c$

4<smiles>C/C=C(\CCC=C1CC1)c1ccccc1</smiles>

1d<smiles>C=C(CCC=C1CC1)COC</smiles>

1e<smiles>CC1=CC(Cc2ccccc2O)CC1</smiles>

1f
$2 \mathbf{a}$<smiles>C=CC1(C(Cc2ccccc2)C(=C)C)CC1</smiles>

$2 \mathbf{b}$<smiles>C=CC1(C(CC)C(=C)CC)CC1</smiles>

2c<smiles>C=CC(C)(C)C(C)C(=C)c1ccccc1</smiles>

2d<smiles>C=CC1(CC(=C)COC)CC1</smiles>

$2 e$<smiles>C=CC1(C(Cc2ccccc2O)C(=C)C)CC1</smiles>

2f
90

89

87 84 70 


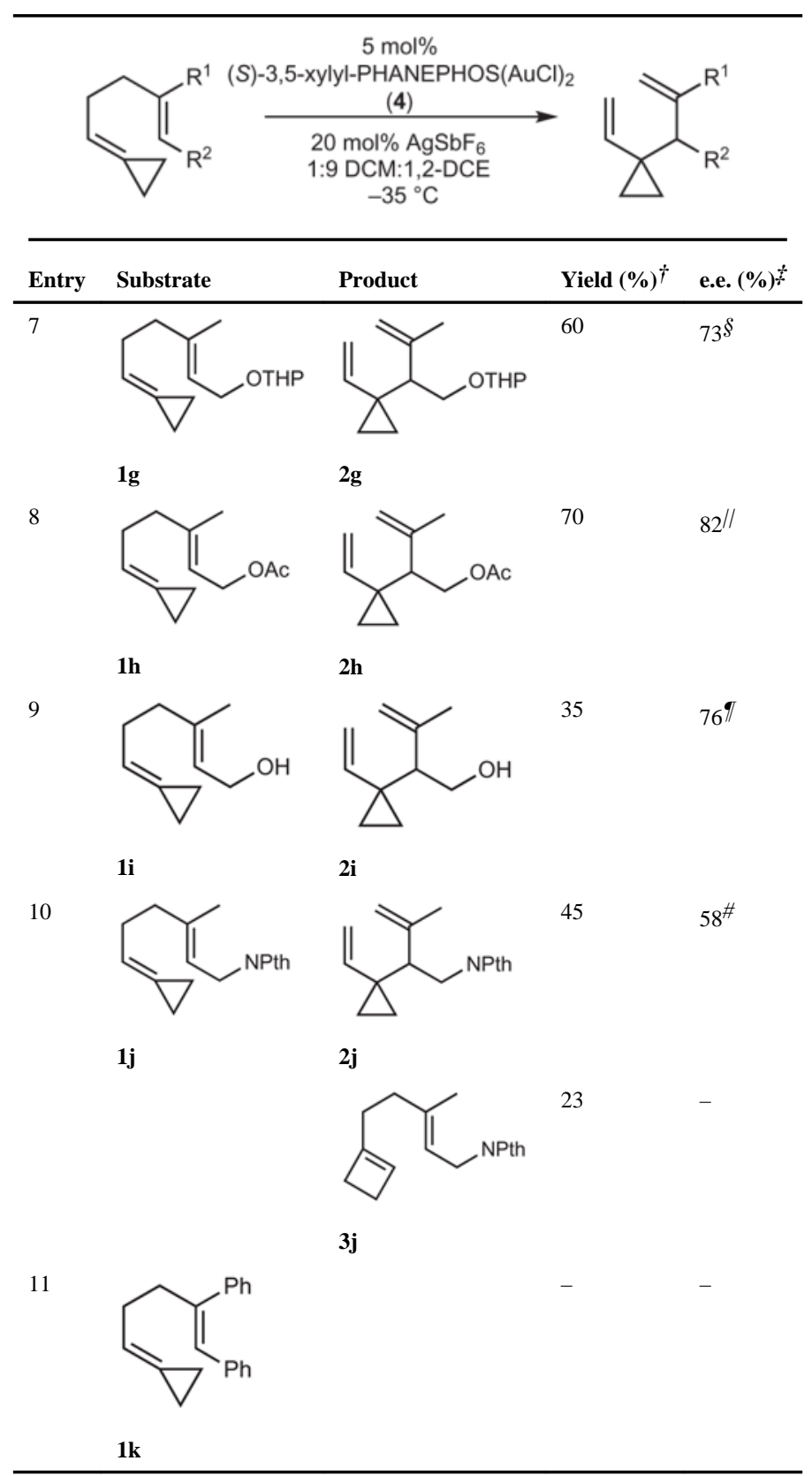

\footnotetext{
* Reaction conditions: catalyst (5 mol\%), AgSbF6 (20 mol\%), 1:9 DCM:1,2-DCE, $-35^{\circ} \mathrm{C}, 18$ hours.

${ }^{\dagger}$ Isolated yield.

*e.e. determined by chiral GC.

$\S_{72 \text { hours at }-35^{\circ} \mathrm{C}, 1: 1 \text { diastereomeric ratio. }}$

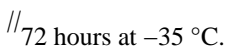

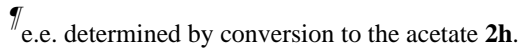

\# e.e. determined by chiral supercritical fluid chromatography.
} 


\section{Table 3}

Gas-phase free energies for thermal [3,3]-sigmatropic rearrangements of substituted alkenylmethylenecyclopropanes. ${ }^{*}$

\begin{tabular}{lll}
\hline $\mathrm{R}^{1}=\mathrm{R}^{2}=\mathrm{Me}$ & $\Delta \boldsymbol{G}^{\ddagger}\left(\Delta \boldsymbol{H}^{+}\right)$ & $-3.6(-6.2)$ \\
$\mathrm{R}^{1}=\mathrm{H}, \mathrm{R}^{2}=\mathrm{Me}$ & $35.1(30.1)$ & $-4.4(-6.0)$ \\
$\mathrm{R}^{1}=\mathrm{Me}, \mathrm{R}^{2}=\mathrm{H}$ & $32.1(32.4)$ & $-7.0(-7.5)$ \\
$\mathrm{R}^{1}, \mathrm{R}^{2}=\mathrm{H}$ & $33.4(30.1)$ & $-7.3(-8.4)$ \\
\hline
\end{tabular}

* Using the DFT M06-2X/6-31G(d) method. 